\title{
Тимошевский А.А. \\ Систематизация официальных документов и научно-методических материалов по COVID-19 для медицинских работников разных специальностей
}

Научно-исследовательский институт организации здравоохранения и медицинского менеджмента Департамента здравоохранения города Москвы

(Россия, Москва)

doi: 10.18411/trnio-01-2022-224

\section{Аннотация}

В статье проведена попытка систематизации поиска нормативных, организационных и методических документов, связанных с термином «Covid-19», представленных на официальных сайтах организаций, министерств и ведомств, а также научных и научнометодических работ доступных в научной электронной библиотеке eLIBRARY.RU по тематике «медицина и здравоохранение».

Ключевые слова: Covid-19, пандемия, коронавирусная инфекция, электронная библиотека, официальный сайт.

\section{Abstract}

The article attempts to systematize the search for regulatory, organizational and methodological documents related to the term "Covid-19" presented on the official websites of organizations, ministries and departments, as well as scientific and scientific-methodical works available in the scientific electronic library eLIBRARY.RU on the topic "medicine and health care".

Keywords: Covid-19, pandemic, coronavirus infection, electronic library, official site.

Продолжающаяся с 2020 г. в Российской Федерации эпидемия, обусловленная новой коронавирусной инфекцией, привела к введению ряда мероприятий, в рамках противодействия данной чрезвычайной ситуации (ЧС), что также явилось причиной разработки новых нормативных, организационных, методических документов, появлению научных и научно-методических работ, связанных с терминами «Covid-19», «пандемия», «коронавирусная инфекция», «ликвидация последствий ЧС» и др.

Ликвидация любой чрезвычайной ситуации, в том числе эпидемии, в первую очередь, предполагает медико-санитарное обеспечение населения. Что означает проведение комплекса мероприятий по ликвидации медико-санитарных последствий ЧС, охватывающих проведение органами здравоохранения организационных, эвакуационных и санитарнопротивоэпидемических (профилактических) мероприятий по устранению непосредственной опасности для жизни и здоровья людей, созданию благоприятных условий для успешного их последующего лечения и реабилитации [1].

Оказание медицинской помощи в этих условиях требует дополнительной профессиональной подготовки и переподготовки существующих специалистов, во многих областях здравоохранения. Это оказание специализированной, в том числе высокотехнологичной медицинской помощи, организация здравоохранения, осуществление санитарно-эпидемиологического надзора, фармация и др.

Своевременное получение информации о новой коронавирусной инфекции медицинскими работниками любых специальностей является неотьемлемой составляющей успешного оказания медицинской помощи. Эти материалы могут быть получены из многочисленных официальных источников. Для получения информации медицинскими работниками различных уровней и специальностей, важно правильно расставить приоритеты в поиске исходных данных.

Источниками информации являются, во-первых, органы управления и организации, которые по роду своей деятельности являются генераторами официальных документов: Всемирная организация здравоохранения (ВОЗ), Правительство РФ, Министерство 
здравоохранения РФ, региональные министерства здравоохранения, Федеральная служба по надзору в сфере защиты прав потребителей и благополучия человека.

Во-вторых, в стране и мире проводится большое количество конгрессов, конференций, онлайн-семинаров на которых обсуждаются проблемы, связанные с коронавирусной инфекцией. По запросу «Covid-19» только научная электронная библиотека eLIBRARY.RU по тематике «медицина и здравоохранение» выдает более 16000 источников литературы. [2].

Профильной организацией, направляющей и координирующей международную работу в области медицинского обеспечения в чрезвычайных ситуациях является Всемирная организация здравоохранения, которая в период 2020-2021 гг., выпустила более 150 методических рекомендаций руководств, протоколов и других материалов, доступных на официальном сайте и переведенных на русский язык.

Наиболее обширная часть документов ВОЗ - это «Технические руководящие указания» [3]. Их можно распределить по предназначению на следующие группы (рис.1).

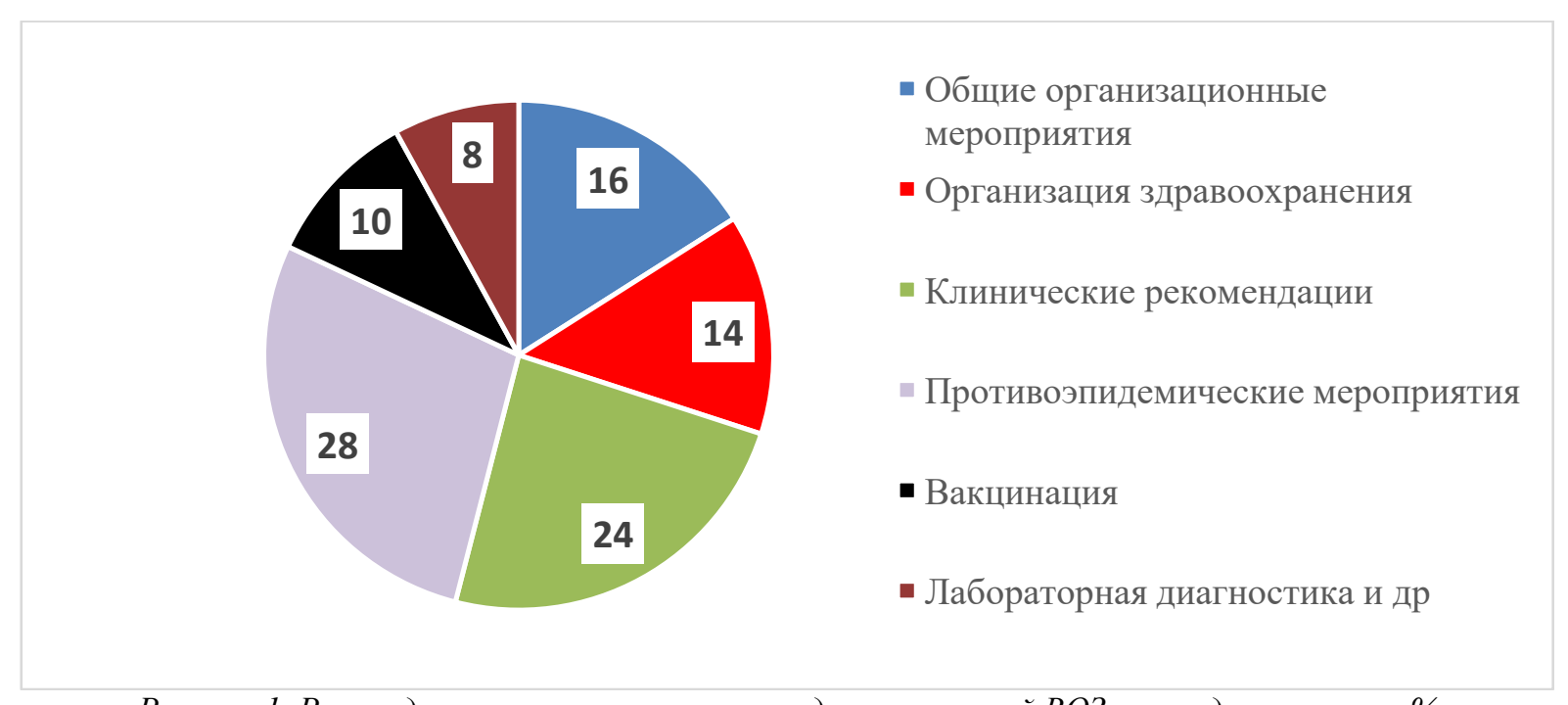

Рисунок 1. Распределение технических руководящих указаний ВОЗ по предназначению, \%

Основной формой документов ВОЗ являются временное руководство, временные рекомендации, краткое руководство, научная справка и др. Конечно, документы ВОЗ носят рекомендательный характер, и в первую очередь интересны для специалистов министерств здравоохранения стран, а также специалистов научных и образовательных организаций.

Министерство здравоохранения РФ разработало ряд официальных документов, в частности методических рекомендаций, которые широко представлены на сайте министерства [4].

Неоспоримо одним из главных документов являются «Временные методические рекомендации профилактика, диагностика и лечение новой коронавирусной инфекции (COVID-19)», которое за период 2020-2021 гг. обновлялись более 12 раз. Сейчас доступна 13.1 версия. Кроме того, на данном сайте представлено еще 7 методических рекомендаций для медицинских специалистов в области терапии, педиатрии, акушерства, эпидемиологии, проведения диспансеризации населения, статистики, реабилитации пациентов. В частности это: «Порядок проведения вакцинации взрослого населения против COVID-19»; «Организация оказания медицинской помощи беременным, роженицам, родильницам и новорожденным при новой коронавирусной инфекции COVID-19»; «Методические рекомендации по организации проведения профилактических медицинских осмотров и диспансеризации в условиях сохранения рисков распространения новой коронавирусной инфекции (COVID-19)»; «Лекарственная терапия острых респираторных вирусных инфекций (ОРВИ) в амбулаторной практике в период эпидемии COVID-19»; «Особенности клинических проявлений и лечения заболевания, вызванного новой коронавирусной 
инфекцией (COVID-19) у детей»; «Методические рекомендации по кодированию и выбору основного состояния в статистике заболеваемости и первоначальной причины в статистике смертности, связанных с COVID-19»; «Медицинская реабилитация при новой коронавирусной инфекции (COVID-19)».

Региональными министерствами здравоохранения также своевременно публикуются новые материалы по оказанию различных видов медицинской помощи населению. Так, на сайте Департамента здравоохранения г. Москвы (ДЗМ), доступно более 20 документов, посвященных данной проблеме (рис.2.).

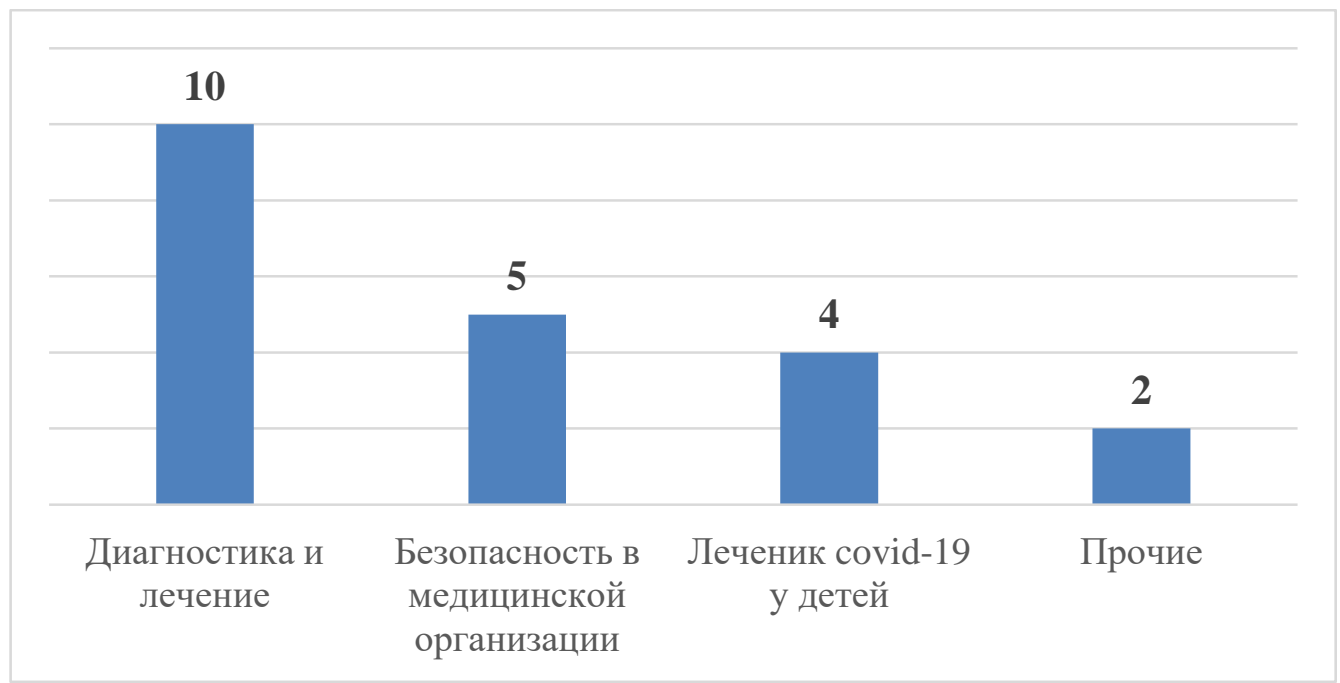

Рисунок 2. Распределение официальных документов ДЗМ, посвященных COVID-19 по предназначению

Это временные методические рекомендации, клинические протоколы лечения Covid19 у взрослых и детей, оказание специализированной медицинской помощи в условиях новой коронавирусной инфекции: педиатрической, хирургической, урологической, акушерской, нейрохирургической и другие методические материалы (правила, алгоритмы) для оказания медицинской помощи, проведения инструментальных и лабораторных методов диагностики, патологоанатомических исследований [5].

Если официальные документы Министерства здравоохранения РФ и региональных министерств в большей степени предназначены для организации и оказания медицинской помощи в амбулаторных и стационарных условиях, то официальный сайт Федеральной службы по надзору в сфере защиты прав потребителей и благополучия человека, публикует массив официальных документов РФ, разработанных в период пандемии коронавирусной инфекции, для специалистов в области обеспечения санитарно-эпидемиологического благополучия населения, всего около 150 документов (рис.3).

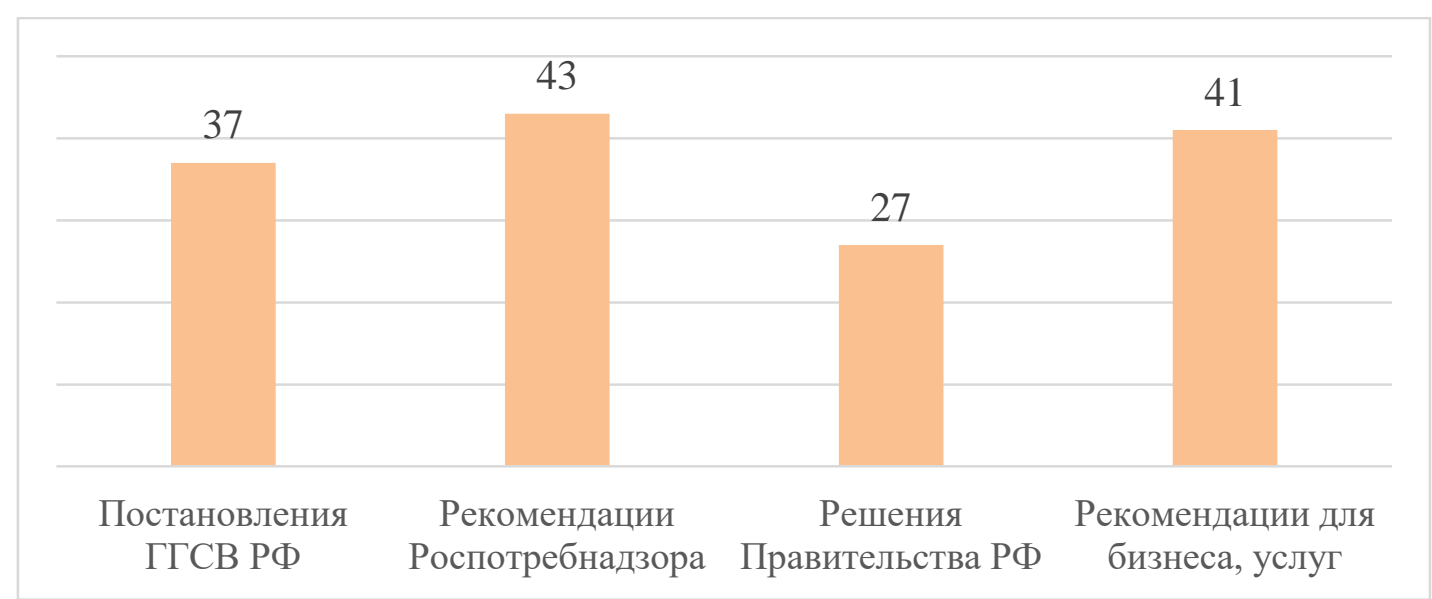

Рисунок 3. Распределение документов официального сайта Роспотребнадзора, по организации деятельности в условиях новой короновирусной инфекции 
Это решения Правительства РФ, постановления Главного государственного санитарного врача РФ (ГГСВ), охватывающие весь спектр противоэпидемических (профилактических) мероприятий, рекомендации Роспотребнадзора для органов, организаций и специалистов, рекомендации для бизнеса (услуги, торговля, туризм, транспорт, образование, строительство) в условиях сохранения рисков распространения COVID-19 и др. документы [6].

Кроме того, на официальных сайтах ВОЗ, Министерства здравоохранения РФ, Роспотребнадзора, региональных министерств здравоохранения, можно найти большое количество информации для граждан по действиям в период эпидемии коронавирусной инфекции, что так же может быть использовано медицинскими работниками для разъяснительной работы с населением, в частности специалистами Центров здоровья.

Наиболее обширной и доступной базой данных по «COVID-19» в РФ является научная электронная библиотека eLIBRARY.RU. B ней отражаются данные статей в журналах, монографий, диссертаций, отчетов, материалов конгрессов и конференций.

В библиотеке по интересующей тематике «медицина и здравоохранение» выдается более 32000 источников литературы, в частности по запросу «COVID-19», найдено 16216 (51\%) [2], «Пандемия» - 9528 (29\%), «Коронавирус» - 6549 источников (20\%).

Кроме того, можно сформировать различные комбинации запросов в частности «COVID-19 лечение», «COVID-19 профилактика», «COVID-19 эпидемиология», «COVID-19 вакцинация», «COVID-19 диагностика», «COVID-19 организация», «COVID-19 мероприятия», «COVID-19 экономика», «COVID-19 политика» и т.д. (рис.4).

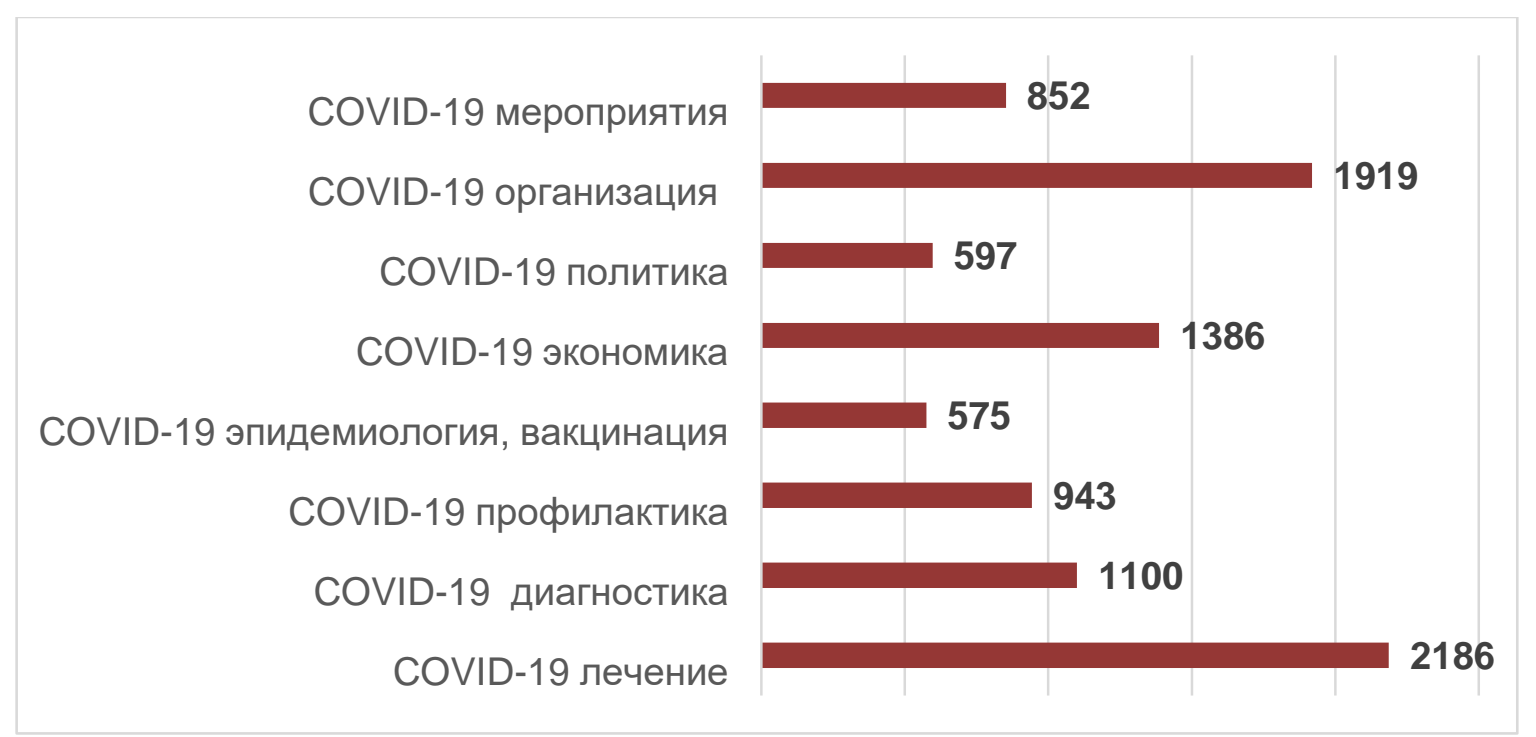

Рисунок 4. Распределение материалов по запросам в библиотеке еLIBRARY.RU

Таким образом в библиотека eLIBRARY.RU. по тематике «медицина и здравоохранение» наибольшее количество материалов определяется по запросам «COVID-19 лечение» - 23\%, «COVID-19 диагностика» - 12\%, «COVID-19 организация» - 20\%, «COVID19 экономика»- $15 \%$.

Конечно, основными потребителями материалов научной электронной библиотеки являются специалисты, ведущие научную работу и профессорско-преподавательский состав высших учебных заведений, использующие новую информацию для расширения и корректировки учебных и учебно-методических материалов.

Для пользователей не зарегистрированных или не адаптированных к использованию данных научной электронной библиотеки, имеется возможность обращаться к официальным сайтам большинства научных медицинских журналов, многие из которых предоставляют бесплатный доступ к архивам номеров, имеют удобный интерфейс для проведения тематических выборок и полнотекстовый доступ к опубликованным статьям. 
Естественно, важным является факт доступности большинства вышеуказанных документов в глобальной сети-интернет.

$$
* * *
$$

1. Медицина чрезвычайных ситуаций (организационные основы): учебник / И.М. Чиж, С.Н. Русанов, Н.В. Третьяков. [и др.] - Москва: ООО «Издательство «Медицинское информационное агентство», 2017. - 400 с.

2. COVID-19./ https://elibrary.ru/query_results.asp.

3. Всемирная организация здравоохранения https://www.who.int /ru/emergencies/diseases/novel-coronavirus2019/technical-guidance.

4. Информация о новой коронавирусной инфекции для медицинских работников /https://minzdrav.gov.ru/ministry/med_covid19.

5. Коронавирус: информация для специалистов/ https://mosgorzdrav.ru/professional/covid-19.

6. Официальные документы Российской https://www.rospotrebnadzor.ru/region/korono_virus/koron_ofdoc.php.

Федерации 